\title{
Condiciones del cumplimiento de la libertad condicional en Argentina. Un período de transición
}

\author{
Beatriz Kalinsky*
}

\begin{abstract}
RESUMEN
Se bace una sistematización y puesta a punto de la literatura científica junto con hallazgos de investigación empirica propios acerca del periodo postcarcelario, llamado en Argentina de "libertad condicional", que se inicia, si se han cumplido los requerimientos necesarios, una vez completadas las tres cuartas partes de una sentencia condenatoria. Este período es crítico, ya que la sociedad-vecindario, barrio, comunidad-presenta, en distintos niveles y grados, obstáculos que la ponen a prueba y en riesgo; esa libertad es "condicional" debido a que, quebrantados algunos de los requerimientos, la cárcel será donde se cumpla el resto de la pena. La transición desde la situación carcelaria a la vuelta a la vida en sociedad no es un trámite meramente administrativo; significa un reacomodamiento veloz y muchas veces inalcanzable de las maneras sociales, institucionales o ideológicas de quienes pasan por tiempo en prisión.
\end{abstract}

Libertad condicional - cárcel - transición

\section{Conditions of probation compliance in Argentina. A transitional period}

\begin{abstract}
It is a systematization and fine tuning of the scientific literature with our own empirical research findings about the post-prison period, known in Argentina as "probation", which begins, if you have fulfilled the necessary requirements, after completing the three-quarters of a conviction. This period is critical since society, neighborhood and communities-show, at different levels and degrees, obstacles that test and jeopardize that freedom. Is "conditional" because, broken some of the requirements, prison is where they serve the remainder of the sentence. The transition from prison to life in society is not a purely administrative process; means a rapid rearrangement and often unattainable in the social manners and institutional and ideological ways of those who pass through prison time.
\end{abstract}

Probation - prison - transition

* Antropóloga. Doctora en antropología, profesora de la Facultad de Filosofía y Letras de la Universidad de Buenos Aires. Investigadora Independiente del CONICET. Virrey del Pino 2439. 4 "10". (1426) Ciudad Autónoma de Buenos Aires. Argentina. Correo electrónico: beka@arnet.com.ar

Artículo recibido el 13 de marzo de 2012 y aceptado para su publicación por el Comité Editorial el 26 de octubre de 2012. 
no de los lazos que vinculan a la cárcel con la comunidad, en Argentina, es el instituto de la "libertad condicional", es decir, el período que pasan las personas condenadas habiendo cumplido las tres cuartas partes del tiempo establecido por la sentencia, en una libertad a prueba para llegar, si se logra, a agotar la condena fuera de la cárcel (salvo las excepciones contempladas por la Ley No 24660/95 y sus modificatorias en la Ley $\mathrm{N}^{0}$ 26472/11 de ejecución de la pena privativa de la libertad) ${ }^{1}$. En la práctica, en general, es una parte del cumplimiento de la pena-que, sin embargo, tiene para su observancia agencias estatales diferenciadas del sistema penal/penitenciario-, los genéricamente llamados "patronatos de liberados" -que actúan (o debieran actuar) como referentes durante su transcurso, con el fin (en la teoría) de que sea una etapa lo más alejada posible del transcurrir carcelario. En otras palabras, el período extramuros es una continuación del cumplimiento de la pena, pero su seguimiento se ha adjudicado a instituciones independientes del sistema penal/penitenciario.

Debido a este malentendido, cualquier infracción de los requisitos que se deben cumplir-fijar domicilio, tener trabajo en regla, no salir de noche, abstenerse del consumo de drogas y alcohol, asistir a programas contra las adicciones- es suficiente para retornar a la cárcel y completar allí la condena. De esta forma, la libertad condicional se vive bajo la constante amenaza de la vuelta a la cárcel. Desde el punto de vista jurídico es una prolongación de la cárcel con niveles de sometimiento y estrés parecidos, que se vive bajo una mirada vigilante que conmina a retornar a la cárcel si se violasen alguna de las exigencias con que fueron prevenidos - de acuerdo a la ley- para obtener la libertad condicional en una audiencia especial ${ }^{2}$. Desde el punto de vista social y antropológico, la libertad condicional si no fuera en la práctica una parte de la pena, podría ser un momento de reacomodamiento de las relaciones sociales y de sostenimiento del ahora expreso por parte de la comunidad, para satisfacer las necesidades más apremiantes de las personas en esta situación, y para que ahora el "detenido condicional" 3 pudiera reconsiderar su posición frente a la ley.

Es en este período donde se presentan las circunstancias cualitativamente diferenciadas ya sea para desistir -en forma intermitente o definitiva del delito- o bien para abrir puertas a la reincidencia ${ }^{4}$. Las personas con registros criminales permanecen estigmatizadas,

${ }^{1}$ Por ejemplo si se es reincidente, el beneficio se inicia los últimos seis meses de la condena y el instituto se denomina "libertad asistida".

2 Opsal, T. "Women disrupting a marginalized identity: subverting the parolee identity through narrative", en Journal of Contemporary Ethnography, Londres, 40 (2), 2001, 136-167.

${ }^{3}$ Decimos "preso condicional" en vez de "liberado condicional" como, en realidad, se debiera para indicar el conflicto semántico y práctico que hay entre la concepción imperante de libertad condicional como una continuidad de la prisión y otra posible que la considera como una etapa en donde la persona reiniciaría su vida en libertad sin tener como telón de fondo el regreso a la cárcel sino una apertura de opciones y escenarios posibles para ir tanteando y eligiendo ayudado por distintas instituciones, como el "patronato de liberados".

${ }^{4}$ Hasley, M. "Negotiation conditional release. Juvenile narratives of repeat incarceration", en Punishment E Society, Londres, Vol. 8 (2), 2006, pp. 147-181.

Pertisilia, J. When Prisoners come home: Parole and Prisoner Re-entry. Oxford University Press, Oxford, 2003, pp. 1-278. 
excluidas del empleo y de oportunidades educativas por algo que ya hicieron y que no tiene retorno, salvo el arrepentimiento y la asunción de la responsabilidad. Tampoco el prejuicio y el etiquetamiento de que son objeto tienen retorno.

Las investigaciones publicadas sobre este tema coinciden sobre una gama de obstáculos que tendrían incidencia en la reanudación de la actividad delictiva ${ }^{5}$.

La serie de problemas que se encara a la salida de la cárcel puede dar una idea de que si, uno por uno, no se puede hallar una solución viable o sostenida en el tiempo, será esta conjunción de frustraciones la que al final les hará eventualmente volver al camino del delito, ya que no hay condiciones para una estabilización de la vida ${ }^{6}$. Por otro lado, algunos autores consideran que la propia estadía carcelaria es una condición que no debe dejarse de lado en cualquier evaluación sobre el tema de la reincidencia ${ }^{7}$.

Esta puesta a punto de las condiciones del cumplimiento de la libertad condicional es producto tanto de la bibliografía que hemos podido consultar al respecto como de nuestros resultados a los que se arribaron como parte de un proyecto de investigación dedicado a este tema y a otros relacionados con la cuestión del delito y el cumplimiento de las penas privativas de la libertad ${ }^{8}$.

Hemos tratado de cubrir y sistematizar los ítems que son un denominador común a los países del mundo democrático, donde las investigaciones sobre este tema tienen lugar en los campos de las ciencias sociales, criminológicas y penológicas, en el que se incluye Argentina, siendo las variaciones adjudicables a los contextos particulares e idiosincrásicos de cada lugar: por ejemplo, la longitud de las sentencias, las diferencias entre probation (suspensión del juicio a prueba) y "libertad condicional" (tipos de cárceles, especialmente las llamadas de "máxima seguridad", relaciones entre celadores y detenidos, diversos grados de hacinamiento y demás condiciones de convivencia que las agravan ilegalmente, frecuencia del uso y tiempo de detenciones preventivas, etc.).

\section{De LA INVESTIGACIÓN EMPÍRICA}

Nuestra investigación se realizó en la provincia de Neuquén, República Argentina, en el marco de un proyecto mayor acerca de mostrar, en clave antropológica, el proceso

\footnotetext{
5 Leverenz, A. "Neighbourhood context of attitudes toward crime and re-entry", en Punishment $\mathcal{E}$ Society. Londres, 13 (1), 2001, pp. 64-92.

Maruna, Sh. "Reentry as a rite of passage", en Punishment E Society, Londres, 13 (1), 2011, pp. 3-28.

Opsal, op. cit., entre otros.

${ }^{6}$ Richie, B. "Challenges Incarcerated Women Face as They Return to Their Communities: Findings From Life History Interview”, en Crime E Delinquency, Londres, Vol. 47 No 3, 2001, pp. 368-389.

${ }^{7}$ Trulson, Ch.; M. DeLisi; J. Caudill; S. Belshaw; J. Marquart, "Delinquent Careers Behind Bars”, en Criminal Justice Review, Londres, 35 (2), 2010, pp. 200-219.

${ }^{8}$ Financiados por la Universidad de Buenos Aires y el Consejo Nacional de Investigaciones Científicas y Técnicas, CONICET, en distintos momentos de su ejecución. No se enuncian los lugares en que se trabajó por el compromiso de confidencialidad y anonimato asumidos en los respectivos consentimientos informados.
} 
penal/penitenciario/pospenitenciario y su incidencia en el ámbito individual (personal), familiar y comunitario, principalmente.

En esta etapa tuvimos en cuenta la literatura científica producida hasta el momento y encontramos, en los ítems principales, una coincidencia cualitativa con períodos similares, quizá denominados de otra manera, en diversos lugares geográficos y geopolíticos.

\section{Metodología}

Estudiamos la calidad de la libertad condicional tanto en mujeres y varones durante el período de un año y medio. Se analizaron en profundidad 15 casos, 8 mujeres y 7 varones. Se hicieron varias entrevistas a cada uno de ellos, en diferentes tiempos vitales: 1) personas que ya conocíamos y habíamos trabajado con ellas durante su encierro carcelario; 2) quienes estaban a pocos días de haber salido en libertad condicional; 3) quienes cumplían la mitad de su libertad condicional; 4) quienes estaban por finalizarla. Estos últimos tuvieron diferentes resultados: siguieron en libertad condicional hasta firmar su libertad definitiva; y quienes volvieron a la cárcel y tomamos contacto nuevamente con ellos en situación de encierro. No tuvimos oportunidad de presenciar una audiencia de libertad condicional.

La edad promedio de los hombres fue de 33 años.

La edad promedio de las mujeres fue ligeramente menor, de 30 años.

Las penas impuestas también fueron variadas y todas ellas de cumplimiento efectivo: de cinco años hasta 15 años, siendo el promedio de los entrevistados unos 6 años de cárcel de cumplimiento efectivo; llegaron a la libertad condicional luego de un transcurso que podríamos considerar “alto”, Desde luego, se firmó un formulario de consentimiento informado y de confidencialidad de los nombres y apellidos, y estos acuerdos fueron renovados cada tanto, en forma oral como para recordar que lo firmado estaba siempre vigente.

Las entrevistas fueron semiestructuradas con la idea de llevar adelante una narración de los puntos clave que deseábamos contrastar con las investigaciones consultadas. La entrevista que fue aplicada en sucesivas reuniones es la siguiente:

¿Dónde volvió a vivir? Si fue de donde salió: ¿Cómo fue su vuelta al barrio? ¿Tiene apoyos de alguna clase? ¿Tuvo problemas de alguna clase?

¿Cómo se mantiene económicamente? ¿Su vuelta tuvo alguna influencia en los recursos económicos de su núcleo familiar?

¿Tiene dónde vivir?

¿Recibe alguna ayuda económica del Estado?

¿Cuál es su condición de salud? Mejor o peor que antes/durante la cárcel/¿Recibe o no ayuda?

¿Considera que el período en donde estuvo preso ganó algo o perdió algo? En caso de pérdida, ¿Qué considera que perdió durante la cárcel? ¿Piensa que puede recuperarlo?

¿Qué cambios nota en su persona?

¿Qué cambios nota en su familia? ¿Y en sus hijos?

¿Cómo está su estado de ánimo? ¿Tiene proyectos? 
Los clientes y/o proveedores ¿se volvieron a acercar (en el caso de drogas)?

¿Cómo evalúa este período de libertad condicional: tranquilo-ordenado/con conflictos/muy desordenado?

¿Está tentado/a a volver a la actividad por la cual fue detenido/a?

¿Cuál era su situación antes de ser detenido/a? ¿Puede compararla con la actual?

\section{Algunos resultados}

Los hombres fueron quienes dieron una perspectiva más ambigua tanto sobre su período carcelario como la situación que enfrentaban en la etapa de libertad condicional. Como suele suceder tienen, de antes o arman después, una relación sentimental con parejas que afianza la sensación de seguridad para gestionar, ante los tantos obstáculos que se les presentan, su vida y reconfigurar, en parte, una identidad carcelaria que fueron adquiriendo para sobrevivir encerrados. Disfuncional en libertad, aprendieron a des-habituarse de las maneras carcelarias -vestimenta, vocabulario, ausencia de responsabilidad y de obligaciones, respuestas más o menos rápida a reclamos (sobre salud, regímenes de alimentos, toma de medicamentos, asistencia psicológica, trabajo protegido, visitas proveedoras para satisfacer necesidades, y peculio). No sin dificultades manifiestan el deseo de "volver a empezar" junto a su pareja sentimental que resulta en un apoyo vital, incluso para superar algunas consecuencias físicas o psicológicas de la cárcel que no pudieron evitarse aun con la presencia de especialistas: pesadillas, presencia o posición activa tomada en motines y huelgas de hambre, conflictos interpersonales resueltos con violencia, decaimiento generalizado tras el cumplimiento de sentencias largas así como dependencia al alcohol o drogas. Aun cuando no encuentran trabajo, las mujeres les ofrecen un techo, les tramitan un plan estatal para solventar parte de sus gastos, los estimulan a seguir buscando una posición laboral y cuando lo encuentran a persistir con una disciplina y éticas laborales. Los hombres con quienes trabajamos admitieron una gran sensibilidad frente a intentos frustrados de alcanzar algunas metas y la vuelta a su camino delictivo, que en general iniciaron desde muy jóvenes. De ahí que tienen poca vinculación con su familia de origen, por una infancia que les recuerda un tiempo al que no desean volver. Los hombres fueron quienes, en las últimas instancias de su vida carcelaria, dieron un panorama poco delineado, borroso o confuso acerca de las condiciones que iban a enfrentar, poniendo una confianza, quizá excesiva, en sus propias capacidades para sortear el momento, y sin una idea definida de los obstáculos que iban a encontrar.

Ofrecen los datos para cumplir con el requisito de fijar domicilio de forma provisoria y cambian de domicilio sin mencionarlo en las reuniones mensuales a las que están obligados a asistir en el Patronato de Liberados y Excarcelados.

Fueron quienes más se quejaron, al principio de las entrevistas, de estar "mal condenados", ser inocentes, haber "hecho emoción violenta", no haber llamado a un testigo "importante"; y luego hacen lo mismo por el rechazo de la sociedad a brindarles el apoyo que necesitaban, material y emocional; aunque quienes construyeron un lazo firme con las parejas sentimentales, ya sea anteriores al encarcelamiento pero en la mayoría de los casos 
durante y después del encierro, percibieron de forma mediatizada por la impronta subjetiva de sus parejas, este retraimiento de la sociedad a brindarles trabajo y quizá, lo más importante, considerarlos como hombres libres - sin etiquetamientos- dispuestos a darles un trato personal y laboral como personas que ya habían cumplido su deuda con la sociedad.

En otros casos, fracasaron quienes no quisieron o pudieron establecer algún vínculo amoroso, evitando comprometerse de manera continua y estable y que tienen poca relación con sus hijos, aunque en el discurso digan que es lo más importante que tienen. Argumentan que desean no tener relación con ellos para que puedan hacer una vida digna, lejos de un padre que ha transcurrido por el camino del delito, que saben que es doloroso y frustrante, y no quieren esa vida para ellos.

En cuanto a las mujeres, en general, y como indica la literatura habiente, han entrado en el mundo delictivo por razones que tienen que ver con una vida previa de violencia física, simbólica y psicológica: madres que las han mandado a prostituirse para "colaborar con la economía de la casa", las han echado de sus casas porque "seducían" a los padrastros de turno, o porque fueron violadas por estos personajes que son habituales en estas familias en donde la madre prefiere el vínculo marital antes que las hijas sean un estorbo. En otras ocasiones, han "acompañado" a sus eventuales parejas sentimentales, sobre todo en el caso de robos y comercialización de estupefacientes, es decir, que lo han hecho "por amor". En un tercer caso, comercialización de drogas ilícitas, hubo dos mujeres "emprendedoras" donde por sí mismas iniciaron una venta al menudeo, disfrazado de quioscos o pequeños almacenes, donde por detrás vendían droga involucrando en esta actividad a sus propios hijos.

Finalmente, entrevistamos mujeres por el delito de homicidio, habiendo dirigido sus acciones mortales hacia sus parejas o bien hacia sus hijos, tanto recién nacidos como de unos años de edad, siempre antes de iniciar su escolaridad (neonaticidio, infanticidio).

Por lo general, estas mujeres no se quejaron de las sentencias a las que estuvieron sometidas, incluso aquellas a quienes se les sometió a cadena perpetua, que en Argentina tiene en realidad un límite de cumplimiento de entre 13 y 15 años ${ }^{9}$ para iniciar los pedidos de los beneficios que otorga la Ley $\mathrm{N}^{\mathrm{0}} 24660 / 95$ de ejecución de la pena privativa de la libertad y sus modificatorias (Ley No 26472/11). No hablan de sus juicios como lo hacen los hombres, en el sentido de alivianar su responsabilidad penal, sino que o bien aceptan su papel en el hecho delictuoso o bien no hablan en absoluto del delito por el cual han sido condenadas.

La primera y casi excluyente preocupación de las mujeres entrevistadas al salir en el tiempo de la libertad condicional fue la reunificación familiar. Una pena larga, por ejemplo, de cinco o más años, supuso una dispersión de los hijos que quedaron a cargo de familiares o allegados, cuando los había. De lo contrario, fue la justicia de menores quien actuó en la Argentina, ubicando a los niños en familias sustitutas que funcionan en forma provisional durante el período de encarcelamiento de la madre. Sin embargo, en los hechos, estos niños fueron y vinieron con un sinfín de pormenores. Algunos no fueron llevados a visitar a la madre presa y si tenían pocos años fueron perdieron el recuerdo

\footnotetext{
${ }^{9}$ Salvo que la sentencia misma impida el ejercicio de los beneficios de la ley de ejecución penal.
} 
de la primera figura materna con la que, entonces, no desean volver al momento de la libertad condicional de esta última. En otros casos, sí fueron llevados a la visita que resultó traumática por el escenario mismo que impone la cárcel, las reglas de requisa, los tiempos de entrada y salida, habiendo verdaderas escenas de pánico y llanto a la hora de despedirse de su madre. A diferencia de los hombres, ellas encontraron en los períodos carcelarios una cierta situación de estabilidad, que no tuvieron en su vida libre. Se alejaron de la violencia doméstica, ya que en las cárceles de mujeres que hemos visitado se prefiere saldar conflictos en forma argumentativa o presentando recursos a los juzgados correspondientes. Obtienen atención de su salud clínica, ginecológica, dental o psicológica. Aprovechan los talleres, escasos por cierto, que se les ofrecen motivadas por adquirir alguna habilidad para el futuro y esquivar, con voluntad y persistencia, la vía delictiva.

En nuestra experiencia, quienes iniciaron el período de libertad condicional lo hicieron en completa soledad o bien acompañadas por otra mujer (madre, hermanas, amigas o expresas). Sus parejas sentimentales de antaño, algunos de ellos padres de sus hijos, no se hicieron cargo de acompañarlas y ofrecerles alguna ayuda. Así que de a poco fueron tratando de remontar una situación difícil, sino imposible para reunir a su familia, encontrar trabajo, continuar los tratamientos de salud que habían iniciado en la cárcel y ordenar sus prioridades. Este último tema es el que más energía les demandó, ya que la vida afuera se les presentó movediza y cambiante. Si han cumplido con penas largas, hay pocos allegados que les advierten sobre los cambios que hubo, ya sea económicos, tecnológicos o culturales. No tuvieron parámetros para manejar el dinero y menos para encontrar empleo y sopesar la calidad del sueldo que se les proponía. No fue posible preocuparse, a la vez, por mantener el trabajo y concretar la reunificación familiar: porque no hubo tiempo concreto, debido a que debieron pasar muchas horas en los juzgados de menores que son las mismas en que hubiera correspondido estar cumpliendo con sus actividades laborales. Las mujeres entrevistadas encontraron trabajo como empleadas domésticas, en estaciones de servicio para expender combustible o como empleadas en algún comercio que las conocían de antes. Todas trabajaron más horas de las indicadas por la ley, con sueldos bajos, sin retribuciones por horas extras ni beneficios sociales. Si bien solicitaban los permisos correspondientes cuando debían asistir a los juzgados de menores, luego de unos cuantos permitidos, sus empleadores se "cansaron" y declinaron de mantenerles el empleo.

\section{PRESEntación de CASOS}

Estela $^{10}$

Este es el caso de Estela, quien fue detenida junto a su pareja sentimental por una tentativa de homicidio que durante el juicio se transformó en homicidio por la muerte

\footnotetext{
${ }^{10}$ Los nombres en todas las ocasiones son ficticios.
} 
de la víctima. Estela tenía por entonces dos hijos; uno de ellos era un bebé en el momento de la detención. Estela opta por dejarlo afuera, al cuidado de la justicia de menores, quien designa una familia sustituta. Los niños mantienen una relación continua con la madre, la visitan y en ocasiones fueron ella y sus hijos a visitar al padre, condenado por la misma causa, en una unidad de detención masculina. Estela es alcohólica y sabe que tendrá dificultades para volver a la vida libre. De hecho, tiempo antes de acceder a la libertad condicional asiste a un grupo hospitalario que trabaja los problemas que tienen algunas mujeres para hacerse cargo de la crianza de sus hijos. En ese tiempo decía que ir a ese grupo le hacía bien. Al momento de la libertad condicional, "entra" al mundo libre cargada de dudas, miedos y sin ayuda.

Estela ha pasado por situaciones traumáticas desde su infancia, huérfana de todo tipo de vínculo afectivo, incluyendo el intento de apuñalamiento de ella y su primer bebé por parte de su pareja de entonces, padre biológico de la criatura que le deparó un largo tiempo de internación hospitalaria. Su alcoholismo la dejó en la calle, y su segundo hijo nace de las circunstancias de la vida. Es una mujer estresada con condiciones físicas deterioradas por su largo alcoholismo y permanencia en la calle, y sobre todo, que nunca pudo organizarse para formar una familia común y corriente, según lo que ella imagina para su futuro y el de sus hijos.

Allí en poco tiempo más volverá a estar con su marido, también en libertad condicional; un hombre violento que tiene antecedentes penales previos. Lo primero que hace, en su ansiedad de reunir a los hijos, es sacarlos sin previo aviso y sin autorización de la justicia de menores de donde estaban viviendo y se los lleva a estar con ella. Debido a la situación de facto, se acepta que los niños sigan con ella. En este sentido, tampoco hay un seguimiento de parte de la justicia de menores sobre el estado de los chicos. Estela ha querido restablecer de forma compulsiva la relación con sus hijos, como si ellos fueran la única motivación que pudo encontrar para enfrentar las dificultades de la vida en libertad. Sus expectativas no estuvieron centradas en los hijos como "figuras de sentimiento", sino como responsables involuntarios de su reintegración a la sociedad. Los efectos sobre los niños estaban comenzando a hacerse notar, en esta suerte de inversión de roles: ellos se volvieron responsables del cuidado de la madre y de su vuelta a la sociedad. Parece que los esfuerzos de reunir a la familia estarían dando sus frutos. Sin embargo, es en ese momento donde sus sueños comienzan a transformarse en pesadilla. El marido vuelve al alcohol y a los golpes. Los niños abandonan la escuela. Recibe una ayuda social mínima que no le permite alquilar alguna vivienda, y entonces decide, durante los fines de semana cuando los niños no tienen clase, ir a vivir a un refugio para mujeres en situación de violencia, pero del que se sabe su ubicación, sin tener entonces las mínimas garantías para que no se las encuentre.

El caso de Estela se considera de criminalidad ocasional y entonces no recibe tratamiento alguno durante el tiempo del encarcelamiento. El hijo mayor tiene bajo peso y se lo incorpora a un programa de "dietas especiales". La salud de ella empieza a decaer, por falta de alimentación adecuada y, en especial, por el estrés que le causa la falta de salida a una situación que se le hace insostenible. La única salida "laboral" que encuentra es pedir limosna en la puerta de la Catedral los días sábado y domingo a la hora de las 
misas. Estela continúa siendo manipulada por su marido golpeador, y no logra superar una situación en donde ve caer la calidad de vida de sus dos hijos: nutrición, habitación, escolarización. Tiene un tercer hijo, esta vez una niña; cursó un embarazo "de riesgo" aunque no se especifican las condiciones de salud al menos en el expediente de libertad condicional al que tuvimos acceso, previo consentimiento de ella. La niña nace saludable y Estela la recibe y la cuida bien. Ella la imagina como una mujer exitosa, "quizá empresaria". Por ahora, la viste con ropa que le regalan y la alimenta con el dinero que logra reunir durante las misas.

En un primer momento intentó concentrar su esperanza en esta beba que pudo haber constituido un punto de inflexión en la vida de Estela. Tampoco se le brindó apoyo para ayudarla a salir de una situación crónica de violencia.

Estela no ha podido estabilizarse; al contrario, se ha ido precarizando en el año y medio que llevó desde su salida de la cárcel. Está desilusionada y cansada; aunque sigue sosteniendo que va a luchar por sus hijos "hasta el fin". A pesar de que transcurre por una situación que está a la vista de todos, e informada, como dijimos, de "riesgo" nadie por ahora ha encarado en forma decidida y sostenida la búsqueda de soluciones inmediatas. La principal excusa es la falta de recursos para asistirla; aunque tampoco parece haber un trabajo interinstitucional, ya que cada cual se ocupa de sus funciones sin adecuarlas a la situación que enfrentan y menos aún sin la posibilidad de reunir recursos para aplicarlos a un caso en concreto.

Un punto clave que se muestra en el caso de Estela es la comprensión parcial que tiene acerca de las razones de su situación. Ella carga las culpas a su vida de niña de la calle, de no haber conocido a sus padres, ser alcohólica y no haber podido aprender lo necesario para encontrar un trabajo para sostener a sus hijos. La carencia de una familia de origen propia hace que ese deseo de formar una suya sea arrasador, lo que le impide reconocer la medida en que se equivoca, o en que va por una senda más o menos bien dirigida a esta finalidad; pero, sobre todo, como casi todas las mujeres en situaciones parecidas, Estela no tiene una comprensión crítica del peso que las influencias estructurales tienen sobre sus decisiones personales. Los últimos informes de su seguimiento por parte del organismo a cargo consideran que está en una situación "de riesgo". De nuestra parte, durante varios meses no pudimos encontrarla en su constante deambular. La última vez que vimos a Estela estaba mendigando en la puerta de la Catedral; la nena ya caminaba y se la veía vivaz; en cambio ella estaba sentada, con visible conducta de estar o haber estado alcoholizada; no nos reconoció.

\section{Fabio}

Fabio tuvo una infancia no solo de pobreza sino de malos tratos. Era su madre quien se ensañaba con él, siendo aún muy pequeño, propinándole golpizas y, ante todo, tratando de ahorcarlo con la manguera que usaban para regar el jardín. Casi no fue a la escuela y durante toda su infancia tuvo una salud al borde de la desnutrición.

Nosotros lo encontramos ya detenido cuando tenía 28 años. Estaba cumpliendo una condena de 12 años y de acuerdo con la ley de ejecución penal salió en libertad condicional al cumplir los 8 primeros años. 
Si bien no intentamos establecer una determinación entre su infancia y su posterior trayectoria delictiva, es cierto que a partir de los maltratos a que fue sometido huyó de su casa, anduvo por muchos lados, se inició en el uso abusivo del alcohol; también fue aceptado por algunas familias para darle un marco propicio para que fuera a la escuela; todos intentos fracasados. La calle fue, entonces, su único hogar y el alcohol su primer amigo.

Fue asiduo asistente de los burdeles del lugar y fueron esas mujeres quienes terminaron por mantenerlo económica y emocionalmente. Entretanto, sigue con sus actividades delictivas. Finalmente, lo apresan, acusan y condenan por varias causas de robo calificado, por el uso de armas, falsificación de documento público y tentativa de homicidio.

Fabio se había iniciado hacía tiempo en el uso de pasta base (llamada "paco" en Argentina, o sea, pasta de cocaína) y en un momento en que no está "en la realidad" apunta a su mejor amigo y sale la bala, aunque no lo mata pero lo hiere. En la cárcel, Fabio muestra estados de ánimos distintos, cambiantes, aunque priman la furia, el enojo y la hostilidad contra las autoridades del penal como hacia los demás presos.

Desde que lo conocimos se caracterizó por tener mucho cuidado con su aspecto. Mantenía su pelo, muy enrulado, largo y prolijo. Para lucirlo limpio y brillante no solo usaba champú sino también crema de enjuague, dos artículos muy valiosos para él. En una oportunidad se estaba bañando y había dejado la toalla colgada en un gancho fuera del perímetro de la ducha. El grupo de detenidos con quien tenía problemas le sacaron la toalla y al momento de salir de la ducha le tiraron un fósforo encendido en la cabeza, con lo que el pelo le quedó chamuscado y se vio en la obligación de raparse. Si bien le fue creciendo rápido, la humillación sufrida dejó huellas importantes para la continuación de la pena privativa de la libertad. Se volvió un preso rebelde e indisciplinado. Lo cambiaron frecuentemente de celda, ya que no soportaba la convivencia prolongada con los demás presos. Nos permite seguir nuestra relación de investigación durante este nuevo período, aunque notamos que ha disminuido su capacidad cognitiva y simbólica y ya prácticamente no habla, en contraste de la locuacidad de que hacía gala cuando lo conocimos. Se presenta cada mes regularmente a firmar la planilla. A la par no busca trabajo aunque siente la presión de la familia que lo acoge para transcurrir este período -nunca más se vio con su familia de origen-, pero que le va exigiendo que contribuya con la economía doméstica. Al respecto recibe varias advertencias a las que no hace caso. En un baile en un lugar nocturno ("boliche bailantero" ${ }^{11}$ ) al que no puede asistir por las condiciones que le impone la libertad condicional, conoce a una joven y empiezan a convivir casi enseguida. Dice. "No sé si la quiero, pero me presta atención”.

De aquí en más hemos organizado este artículo sistematizando los principales ítems que parecen incidir en el éxito o fracaso de los liberados condicionales. Los hombres y mujeres que hemos entrevistado no han quedado fuera, ni por un momento, de estas

\footnotetext{
${ }^{11}$ Local bailable donde se escucha y baila música cumbia o tropical.
} 
condiciones, viviéndolas de acuerdo con sus historias familiares, experiencia carcelaria y oportunidades de acceder a distintos capitales sociales de sus grupos de referencia. El esfuerzo de este trabajo consiste en organizar y dar una perspectiva consistente a lo ya escrito para el período de libertad condicional; y, en segunda instancia, mostrar en casos concretos, de nuestros resultados de investigación, la similitud de condiciones que se dan también en la República Argentina.

Si bien cada una de ellas está escrita de manera general por organización del texto, nos pareció hacer una enumeración taxativa y consecuencial de los problemas que aquejan a cualquier persona que inicia su período de libertad condicional. Si bien en nuestros entrevistados, como en cualquier otro caso, la intensidad de cada ítem se da con distinto énfasis; sin embargo, las condiciones generales se comparten.

\section{REQUisitos INALCANZABLES}

Los liberados condicionales son personas en quienes los diversos y casi constantes ciclos de violencia (familiar e institucional, principalmente) y las adicciones han interrumpido o nunca iniciado las posibilidades de generación de empleos legales y estables, impedido la escolarización e inhibido las posibilidades de acceso a una vivienda digna ${ }^{12}$.

Uno de los temas más trabajados y denunciados como un obstáculo principalísimo en el fracaso para superar el período de la libertad condicional es el de las dificultades que encuentran las personas recién salidas de la cárcel para encontrar un lugar para vivir y un empleo más o menos estable y en "regla"; y, entre las mujeres, la reunificación familiar ${ }^{13}$. Si no se halla vivienda y trabajo quizá no sea pensable incorporarse al programa de libertad condicional, ya que son requisitos que se deben arreglar previo a la salida. En nuestra experiencia rara vez se encuentran trabajos en regla y más o menos calificados.

12 Nos estamos refiriendo únicamente a la criminalidad convencional.

${ }^{13}$ Añez Castillo, M. A.; Han Chen, P.; Morales Manssur; et al. "Asistencia laboral penitenciaria y postpenitenciaria, una propuesta a la reintegración social del recluso”, en Capítulo Criminológico, Universidad de Zulia, Vol. $36 \mathrm{~N}^{\circ}$ 4, 2008, pp. 51-88.

Birbeck, Ch. "El desempeño penal bajo el destacamento de trabajo en la región andina de Venezuela (1999-2002)", en Capítulo Criminológico. Universidad de Zulia, Vol. 31 N 4, 2003, pp. 33-74, 2003.

Hammett, Th., Ch. Roberts y S. Kennedy, "Health-Related Issues in Prisoner Reentry", en Crimen E Delinquency, Londres, Vol. 47 No 3, 2001, pp. 390-409.

Leal, L.; A. García. "Condiciones objetivas y subjetivas del funcionamiento de la medida destacamento de trabajo desde la perspectiva de los destacamentarios”, en Capítulo Criminológico, Universidad de Zulia, Vol. $36 \mathrm{~N}^{\circ}$ 1, 2008, pp. 11-37.

Maruna, Sh.; R. Immarigeon, (edited by), After Crime and Punishment. Pathways to offender reintegration. William Publishing, Nueva York, 2004, pp. 1-320.

O'Brien, p. Making it in the "Free World", Women in transition from prison. New York State University of New York Press, Nueva York, 2001, pp. 2-201.

Opsal, op.cit, Rossman, S. "Building Partnerships to strengthen offenders, families, and communities, en Travis, J.; M. Waul”, en Prisoners once removed. The impact of incarceration and re-entry on children, families, and communities. The Urban Institute, Washington, 2003, pp. 342-379. 
Una de las jóvenes que fuera nuestra interlocutora tuvo que aceptar el único trabajo que se le presentó en una estación de servicio, llenando los tanques de combustible, en el turno noche. Quedó ubicada en un ambiente poco favorable para una reinserción, debido a que su lugar de trabajo estaba en una ruta muy concurrida. Cuando consiguió el turno de día llegó el invierno, un clima muy frío y nevador, por lo que no pudo mantenerlo. No se le revocó la libertad condicional debido a que no dio cuenta de su "estado laboral". Completó su sentencia extramuros.

Se ha insistido también sobre la escasez o falta de programas para tratar adicciones, en especial al alcohol o las drogas.

Ninguno de los detenidos, en nuestra experiencia de investigación, contó con asistencia psicológica, salvo que fuera una "urgencia", de la que no supimos los criterios para definirla salvo los obvios de intento de suicidio o episodios sicóticos; y en el caso de una urgencia en breves minutos se cerraba recetando antidepresivos, ansiolíticos o drogas antipsicóticas. Si bien se puede contratar este servicio de apoyo psicológico en forma privada o sin pago, es un camino que es difícil de conseguir y, sobre todo, mantener una continuidad aceptable. De lo que pudimos registrar se logró solo en dos casos y se sostuvo unos pocos meses, al ritmo de una vez por semana.

Asimismo, no hay acceso a tratamientos psiquiátricos/psicológicos sea por dolencias anteriores a la condena o sobrevenidas durante el encarcelamiento. Estas necesidades como otras son significativas, a veces severas y siempre urgentes y presentan serias barreras a la reintegración. En el caso de las mujeres, si ellas se han dedicado al mejoramiento de su salud durante la estancia carcelaria, ya no tienen tiempo para asistir a los centros de salud, o tienen dificultades para encontrar los turnos correspondientes, o bien carecen de dinero para su acceso. Son otros ahora los problemas que las agobian a la salida de la cárcel y en su agenda de prioridades van dejando a un lado el cuidado de su salud ${ }^{14}$.

Una entrevistada, en una ocasión, habiendo superado esta carrera de obstáculos, encuentra que el hospital donde tenía que atenderse estaba con sus actividades paralizadas, debido a una buelga que se hacía por mejoras salariales. No lo volvió a intentar.

Los expresos son un grupo cuyas necesidades de oportunidades para tener éxito están severamente disminuidas por el sistema de justicia penal/carcelario; tanto como por las condiciones previas que la situación carcelaria no ha hecho más que reforzar. La falta de conducta institucional de algunos presos, es decir, la persistencia en el delito durante el encarcelamiento (tráfico de drogas, de tarjetas telefónicas, son los dos motivos recurrentes) es un resultado de las biografías, experiencias y características de los

${ }^{14}$ Carlton, B.; M. Segrave, "Women's survival post-imprisonment: Connecting imprisonment with pains past and present”, en Punishment and Society, Londres, 13 (5), 2011, pp. 551-570. 
presos que traen al ambiente institucional, a lo que se suman las presiones de la cárcel en sí misma, comportándose como un factor más que tiene que ver con la reincidencia, una vez liberados ${ }^{15}$.

Un expreso entrevistado, viniendo de una vida delictiva dedicada al robo calificado por el uso de armas y artefactos de guerra, "adaptó" este estilo de vida a la conducta carcelaria, lo que lo empobreció aún más en sus capacidades cognitivas y sus posibilidades de expresar sentimientos. Como hombre "duro" generó situaciones de peligro, fue trasladado numerosas veces a cárceles de cada vez mayor seguridad y cuando por fin accedió a la libertad condicional se incorporó rápidamente a una red local de comercialización de drogas, alcohol y trata de personas. Con él, a pesar de numerosos encuentros durante el período de ejecución de la pena, tuvimos solo dos entrevistas posteriores, ya que viviendo otra vez en un ambiente delictivo se negó a seguir con los encuentros ${ }^{16}$.

\section{CÁrCEl, EXCLUSión y AGENCIAS DEL Estado}

La ayuda social estatal es escasa. Los recursos con que cuentan los genéricamente llamados "patronatos de liberados" son insuficientes tanto en los aspectos materiales como humanos $^{17}$. No tienen a disposición ni proveen de convenios con los organismos responsables de la salud, la vivienda, el empleo y la educación que permita a los "detenidos condicionales”, o aun a quienes ya están en libertad pero estuvieron detenidos, transitar acompañados hasta que puedan incluirse con el resto de la gente; tampoco hay recursos generados especialmente para esta población. De manera tal que al mismo momento que salen en libertad, después de un tiempo transcurrido en un ámbito especial y hermético como lo es la cárcel, tienen que comportarse como una persona que no ha delinquido, ni ha sido condenada ni ha estado presa, es decir, como si su paso por el delito y su estadía carcelaria no hubieran existido. Se tendría que hacer de cuenta de que nunca se pasó por este transcurso que ha incidido en lo recóndito de las identidades individuales y sociales, generando inhabilidades comunicativas y laborales, entre otras complicaciones que debieran superar por convencimiento propio ${ }^{18}$. Adolecen de problemas generados por el encierro, por ejemplo, en la vista por no poder fijarla durante el tiempo de encierro en el horizonte, debido a los muros perimetrales; contracturas musculares generalizadas, cefaleas, irritabilidad a los ruidos fuertes, hipervigilancia,

\footnotetext{
15 Trulson; DeLisi; Caudill; Belshaw, op. cit.

${ }^{16}$ Fue denunciado, oportunamente, por el Patronato de Libertados y Excarcelado correspondiente a la jurisdicción que le correspondía pero se dio a la fuga.

${ }^{17}$ Núñez G. M. "Las fórmulas alternativas de cumplimiento de pena en el sistema penitenciario venezolano”, en Capítulo Criminológico. Universidad de Zulía, Vol. 33 No 1, 2005, 31-53.

para el caso venezolano.

${ }^{18}$ Aunque haya investigadores que plantean la "cárcel terapéutica”. (Smith, P. y M. Schweitzer.) "The Therapeutic Prison”, en Journal of Contemporary Criminal Justice, Londres, Vol. $28 \mathrm{~N}^{\circ}$ 1, 2012, pp. 7-22.)
} 
infección de HIV, tuberculosis, etc. Son problemas generados en la cárcel pero que persisten más allá de ella; además de cualquier enfermedad previa. No hubo un solo entrevistado por nosotros que no padeciera de alguna de estas perturbaciones. Además tienen que actualizarse sobre todo en los recursos tecnológicos, con el simple hecho, por ejemplo, de viajar en el transporte público.

Una mujer que habló con nosotros beneficiada con las "salidas laborales" después de quince años de encierro carcelario, intentó en tres ocasiones llegar en transporte público automotor a su lugar de trabajo pero no lo logró. No tenía a nadie que pudiera acompañarla en tanto las indicaciones que consiguió obtener no las pudo comprender. La tacharon de "vaga", pero creemos que lo que privó fue esa inaccesibilidad que le causó una vergüenza que no pudo superar en ese momento.

Este período podría ser supervisado no solo por las agencias correspondientes en consonancia con los recursos estatales, sino también con los medios que, por su lado, poseen en diferentes medidas y tipos las comunidades, barrios y vecindarios (control informal). No obstante, el miedo al delito en estas comunidades tiene que ver con la posibilidad de la declinación de los valores sociales y a la disminución de la cohesión social que deviene de las normas de convivencia aceptadas.

También las personas en libertad condicional carecen de fuentes genuinas y confiables de información que permitan buscar dónde están los recursos que hay disponibles. Muchas veces llegan al lugar equivocado, con la consiguiente pérdida monetaria, de energía, de tiempo y la carga de frustración que implica para personas que de por sí se han vuelto impacientes y en cierta forma intolerantes a los contratiempos ${ }^{19,20}$.

La criminalización a la que están sometidos es doble. Por un lado, el estilo de vida previo al que se suman los efectos de la cárcel: "exclusión-carcelarización”/“carcelarizaciónexclusión”.

\section{LAS COMUNidAdES DE PERTENENCIA}

Hay un cierto acuerdo entre los investigadores de que las personas que enfrentan el período de libertad condicional vuelven a los mismos lugares desde donde salieron, poco o mucho tiempo después. En cualquier caso encontrarán a su barrio o vecindario en las mismas o peores condiciones de cuando se fueron removidos por la detención ${ }^{21}$. El crimen, los expresos, y ofensores tienden a concentrarse en vecindarios que se caracterizan por altas tasas de pobreza y otras desventajas sociales ${ }^{22}$.

${ }^{19}$ Hipp, J.; Jesse J.; R. Shah; S. Turner, "Parolee's physical closeness to social services. A Study of California parolees”, en Crime E Delinquency. Londres, Volume XX, Number X, 2008, pp. 1-29.

Richie, op. cit.

${ }^{20}$ Lic. Andrea Grossi, comunicación personal. Dirección Provincial de personas judicializadas de la provincia del Neuquén (Argentina).

${ }^{21}$ Hammett, Th.; Ch. Roberts; S. Kennedy, op. cit., Richie, op. cit.

${ }^{22}$ Leverenz, op. cit. 
Se trata de zonas sociales marginales, de empleo de baja calificación o inestable, de insuficiente nivel educativo y de viviendas precarias donde todo el conjunto poblacional hace esfuerzos para sobrevivir y mantener las mínimas condiciones que se necesitan para una vida digna. El hecho de que haya integrantes que han estado condenados es un ingrediente más que desmejora el estatuto social del barrio o vecindario, dejándolo a la vera de las consideraciones políticas en cuanto a la implementación de planes públicos sostenidos en el tiempo y que respondan a las necesidades vitales urgentes y de mediano y largo plazo. A la par, son víctimas -o beneficiarios de acuerdo al punto de vista que se lo quiera considerar- del clientelismo político en cuanto a los planes sociales, los punteros políticos, las "cocinas" de "paco" (como dijimos, pasta base de la cocaína mezclada con cualquier otro ingrediente: viruta, detergente o lo que se tenga a mano) o el tráfico de armas, siendo quizá los niños los más afectados por este deterioro.

En nuestro caso, algunos de las personas en libertad condicional se volvieron a lo que se denomina "tomas", es decir, ocupación de tierras fiscales. Se generan muchos conflictos frente al "dueño" de la toma (o sea el primero que se instaló allí) al que se le "alquilan" o "compran" predios. Las normas de convivencia son inexistentes y las pocas que bay son dependientes de los avatares políticos coyunturales. Algunos de los expresos hombres decidieron cambiar de lugar de pertenencia en barrios o comunidades en donde sabian que no eran bien vistos o directamente rechazados, teniendo que usar la fuerza física o verbal para "bacerse" de un "terrenito" para iniciar "una nueva vida" aunque fuera a los golpes, para asegurarse que lo podrían vender después y comprar algo un poco mejor. Las habitaciones eran del todo precarias y fueron mejoradas con el esfuerzo de sus parejas mujeres, ya que ellos no pudieron encontrar trabajo, salvo algunos encargos mínimos y mal remunerados ("changas"). En un caso, el hombre intentó un microemprendimiento, donde la mujer hacía alguna comida que él vendía en las obras en construcción en la ciudad capital a unos 20 kilómetros de donde estaba la "toma". Iba en bicicleta o caminando cualquiera fuera el clima imperante. Con la disminución drástica de la actividad de construcción de estos últimos años, ya no pudieron "hacer algunos pesos" para sobrevivir y mantener los bijos a cargo; dos de ella, uno de los cuales era minusválido y dos de él, todos de parejas anteriores. En la actualidad viven de los planes sociales otorgados por el Estado Nacional o provincial que son de escaso monto pero además de una fuerte inestabilidad de acuerdo a la retribución política que las personas estén dispuestas a dar.

El ahora "preso condicional" necesita encontrar soluciones a sus necesidades en un ambiente que no es propicio para hallarlas; no solo en cuanto a los recursos habitacionales o laborales sino al humor del colectivo, barrial o vecinal que pocas veces le da un buen recibimiento. Lejos de darles la bienvenida, salen de sus caminos con miedo y enojo. Quienes vuelvan de la cárcel traen consigo una carga imprevisible de frustración, exigencias y expectativas que con el correr del tiempo puede transformarse en incomunicación y violencia. En estas situaciones, nadie puede ponerse en la perspectiva de quien intenta incluirse, de repente, en el flujo diario de una comunidad de la que estuvo ausente por un tiempo muy particular (delito/cárcel), en la que su propia contribución estuvo ausente 
y de la que se espera, quizá, demasiado. Tampoco él o ella pueden ver la situación desde la perspectiva de los otros, ya que está transcurriendo por un momento excepcional donde se juega su libertad; para ello intenta reconstruir una reputación social, familiar, individual que quizá nunca tuvo como integrante, ciudadano "parcial", ya que puede exigir sus derechos pero no cumplir con sus obligaciones por su estado de vulnerabilidad de una comunidad, pero que ahora necesita para mantenerse en libertad y quizá librarse, en forma definitiva o temporaria, del camino del delito.

\section{COMUNidAd Y CÁRCEL}

La cárcel se inmiscuye y actúa en forma negativa en los lugares de residencia de los presos, y después "presos condicionales", donde suelen seguir viviendo sus familias y conocidos durante el tiempo de la condena. El barrio de alguna forma se "carcelariza" por un contacto mediato con los detenidos y pareciera que la cárcel amplía sus bordes más de lo que indican sus límites perimetrales ${ }^{23}$.

A la par, un vecindario estigmatizado porque sus miembros suelen tener más relación con el sistema "penal/carcelario" no sobresale por la calidad de vida de sus integrantes. Se establece una relación entre delito y criminalización, esta última considerada como la cantidad de personas que pasaron por la cárcel. Y se va deteriorando su condición de ciudadanía con lo que van perdiendo, en los hechos, su capacidad a reclamar, ser escuchados y así plantear sus derechos en la arena pública. Esta cuestión no deja a nadie, que integre ese vecindario, indemne ${ }^{24}$.

La debilidad de los lazos sociales, en forma de ayuda mutua, solidaridad vecinal e integración de las diferentes esferas de la vida cotidiana afloja los controles informales por los que la gente logra establecer los criterios de convivencia. Se imponen valores contrarios como el individualismo y la desintegración de los esfuerzos por perseguir alguna mutualidad de acciones y prácticas; situación que a su vez configura un escenario apto para la violencia y el delito ${ }^{25}$.

Cuando preguntamos a uno de los entrevistados varones más jóvenes cómo pensaba actuar frente al rechazo del barrio que él mismo nos terminaba de narrar, su respuesta fue rápida: "por la fuerza, a los golpes, si hay que matar a alguien lo hago porque mi familia tiene que vivir en algún lado y mi familia está primero que nada".

${ }^{23}$ Clear, T., D. Rose; J. Ryder, "Incarceration and the Community: The Problem of Removing and Returning Offenders", en Crime E Delinquency, Londres, $\mathrm{N}^{\circ} 47, \mathrm{~N}^{\circ} 3,2001$, pp. 335-351.

${ }^{24}$ Haney, C. "The contextual revolution in psychology and the question of prison effects", en Liebling, A.; Sh. Maruna. The effects of Imprisonment. William Publishing, Nueva York, 2005, pp. 66-93.

${ }^{25}$ Taxman, F.; D. Young; J. Byrne. "With eyes wide open: formalizing community and social control intervention in offender reintegration programmes”, en Maruna, Sh. y R. Immarigeon, (edited by), After Crime and Punishment. Pathways to offender reintegration. William Publishing, Nueva York, 2004, pp. 233-260. 
Ante nuestra pregunta acerca de si no podía acceder a otro lugar, donde no lo conocieran y fuera medianamente bien recibido y se desempeñara como colaborador para el mejoramiento de la situación habitacional, de salud y de condiciones de vida en general, nos aseguró que como ya habia comprado (aunque ilegalmente, es decir, sin papeles reconocidos y legales) no tenía por qué irse. Estaban todos en las mismas condiciones y la única opción que tenía en mente era violencia como solución del conflicto. Dijo: "En esos lugares no podés hablar, tenés que actuar" (fragmentos dichos en el contexto de una de las entrevistas a P., 25 años, a tres meses de su libertad condicional, marzo de 2010).

\section{VIII. "PRESOS CONDICIONALES" Y FAMILIAS}

El soporte familiar es en general un factor que se pondera positivo ${ }^{26}$. Se considera que los lazos familiares que se mantienen durante el encarcelamiento brindarán un mayor sustento durante el período de libertad condicional y la posterior libertad definitiva. Estos autores consideran que las visitas familiares son altamente beneficiosas tanto para el detenido como para sus hijos, facilitando así el reingreso a la familia y a la sociedad libre cuando llegue el momento.

Sin embargo, creemos que en la literatura académica no se consideran suficientemente los casos de violencia y abuso infantil, conyugal, parental, u otras situaciones que indicarían que la vuelta del integrante de la familia acusado de tal delito, o de otro, pero que se comporta de forma violenta puede no solo no ser bienvenida sino inconveniente para el bienestar de la familia. Es posible que esta familia haya recompuesto los vínculos después de su remoción, quizá con una nueva pareja sentimental y nuevos hijos, con un largo y difícil trabajo emocional/vincular y no quiera destruir lo ya logrado.

No hay casi investigación social sobre estas familias con un miembro preso que fue previamente violento y las consecuencias de su retorno. No se ha examinado tampoco en profundidad cómo los "presos condicionales" y los miembros de su familia renegocian sus relaciones. De hecho, el encarcelamiento puede eliminar situaciones violentas que ocurrían dentro del hogar o en el vecindario, y de últimas, se trataría de un hecho -la remoción de la persona en cuestión-que trae sus posibles beneficios secundarios ${ }^{27}$.

\footnotetext{
${ }^{26}$ Birbeck, op. cit., Colmenarez Isturiz, J. "Actitud familiar ante la llegada del liberado al hogar (Estudio de casos)”, en Capítulo Criminológico, Universidad de Zulia, Vol. 33, No 1, 2005, pp. 79-113.

Mills, A.; H. Codd "Prisoner's families and offender management: mobilizing social capital", en Probation Journal. The Journal of Community and Criminal Justice. Londres, Vol. 55 number 1, 2008, pp. 9-24.

O’Brien, op. cit., Rossman, S. "Building Partnerships to strengthen offenders, families, and communities, en Travis, J. y M. Waul, Prisoners once removed. The impact of incarceration and re-entry on children, families, and communities. The Urban Institute, Washington, 2003, pp. 342-379.

Travis; Waul op. cit., Vigne, N.; R. Naser; L. Brooks; J. Castro. "Examining the Effect of Incarceration and In-Prison Family contact on Prisoner's Family relationships", en Journal of Contemporary Criminal Justice, Londres, Vol. $21 \mathrm{~N}^{\circ}$ 4, 2005, pp. 314-335.

27 Comfort, M. "Papa's house". The prison as domestic and social satellite", en Ethnography 3 (4), Londres, 2002, pp. 467-499.
} 
La familia puede sentirse, o lo está, estigmatizada, debido a las dificultades que tiene que enfrentar para aceptar o integrar toda la situación delictiva; siente entonces opresión, vulnerabilidad y, en algunos casos, culpa y vergüenza.

Además, la actitud tomada por el grupo familiar frente al regreso del integrante previamente encarcelado puede ser producto del tipo de delito cometido, su magnitud, el tiempo que pasó en prisión, la responsabilidad que asume ante el hecho cometido, la exposición pública y mediática en la que se vio involucrada la familia por el hecho, así como los antecedentes delictivos de la persona en cuestión ${ }^{28}$.

Dos hombres entrevistados prefirieron mantenerse en silencio respecto de las formas que tomaron sus reingresos aceptando que su familia habia cambiado y su autoridad, como padre, estaba anulada. No eran reconocidos ni siquiera como miembros legítimos del grupo familiar que bicieron todo lo posible para quedar fuera de las contingencias de la situación. No supimos si ellos fueron previamente golpeadores o abusadores antes de cometer el delito por el que fueron encarcelados, y tampoco nos pareció el momento de entrevistar a sus familias debido a que hacía solo unos días que estas personas estaban en libertad condicional. Pensamos que podríamos ser percibidos como que íbamos "de parte" de ellos para permitir su ingreso a las familias. Este tema estaba totalmente fuera de nuestras intenciones.

Uno de ellos se fue a vivir a la casa de su madre reavivando la mala convivencia que habian tenido desde siempre y en el otro caso, un amigo le ofreció una babitación pero con los días esa relación también se fue desgastando por su nulo aporte económico pero sobre todo por su aparente desinterés según su amigo en las búsquedas laborales. Ambos terminaron viviendo en la calle aunque no informaron a la autoridad de control correspondiente.

En síntesis, la familia puede sentirse ansiosa por tener que cargar con un problema adicional si tiene que apoyar al ahora expreso, especialmente en circunstancias donde sienten que no tienen nada que ofrecer como respuesta o que dichas eventuales respuestas pueden perjudicar el equilibrio generado después de la remoción de la persona. Ver a la familia, en todos los casos, como una potencial fuente de apoyo es al menos apresurado, ya que además de estar profundamente estresada debe cargar con la responsabilidad de asistir la gestión del preso durante la libertad condicional ${ }^{29}$.

\section{Cadenas intergeneracionales}

La parentalidad pobre ${ }^{30}$ sufrida por la persona encarcelada y ejercida luego sobre sus propios hijos puede ser otro factor que juegue de manera negativa en la reintegración del integrante removido de la familia durante su encarcelamiento.

\footnotetext{
${ }^{28}$ Vigne; Naser; Brooks; Castro, op. cit.

${ }^{29}$ Mills; Codd, op. cit.

${ }^{30}$ O'Brien, op. cit., Travis y Waul, op. cit.
} 
Si las relaciones con sus propios padres, sea el detenido hombre o mujer, han sido débiles, dañinas o inexistentes es difícil establecer otro tipo de vínculos con sus propios hijos al tiempo de ser padres ellos mismos. La cadena intergeneracional también se expresa en este rasgo. La pobreza en los lazos parentales tiene que ver con el capital social que tiene disponible, genera o puede movilizar una familia para el desarrollo cognitivo, emocional y social de los hijos ${ }^{31}$. Al carecer de un modelo de parentalidad exitoso, en el sentido de riqueza simbólica y emocional, estas personas no tienen forma de comparar sus tareas, riesgos y éxitos como padres más que con los aspectos negativos $y$, si se quiere, siniestros de sus respectivas experiencias. No logran cualificar sus logros al interior de su propia familia, por más que conozcan "de afuera" modelos alternativos de parentalidad que les puedan servir de ejemplo, pero no de apoyo ni comparación. En este nivel, solo se puede comparar con lo que se tiene, se ha vivido y experimentado ${ }^{32}$.

El déficit en la percepción sobre su "poder-hacer", dificultades para tomar decisiones, exigencias desmesuradas de los demás, utilización de formas de escape como el alcohol o las drogas no son factores que estén al alcance de la voluntad, ya que no hay una cabal comprensión de sus razones y consecuencias.

Núcleos familiares completos han tenido contacto con el sistema penal/carcelario.

En nuestro estudio encontramos dos grupos familiares en donde el padre de familia y casi todos los hermanos estuvieron o están implicados con el sistema penallcarcelario ${ }^{33}$. Siempre habia uno o dos hermanos en la cárcel en tanto los demás continuaban con sus actividades delictivas. Un miembro de uno de estos grupos domésticos delictivos, en una entrevista durante su libertad condicional, dijo en tono mezclado de cinismo y broma, que debia ser algo "contagioso". Dos de sus ocho hermanos habian huido a países limítrofes hasta la prescripción de su causa. Pero se mantenían en contacto e incluso quiso darnos sus direcciones postales, como si se sintiera o se supiera impune (inmune al poder de la ley). No encontró ninguna otra explicación posible en tanto que el concepto de "contagio" lo desarrollo, avanzando la entrevista, como que cada bermano daba un ejemplo "no bueno", según sus propias palabras, que los demás iban imitando. Acotó que, a veces, su madre se preguntaba qué había hecho mal para que todos sus bijos bubieran seguido el camino delictivo. No pudimos hablar con ella porque, según nuestro entrevistado, se encontraba enferma, sin disposición para hablar, pero en cuanto se recuperara íbamos a ser muy bien recibidos. Todavía no bemos podido concretar la reunión. En las dos unidades familiares delictivas habia habido parientes cercanos detenidos que llegaban hasta sus abuelos (ascendientes) y, abora, algunos de los hijos de la generación que pudimos entrevistar representados por algunos miembros (contemporáneos), estaban ya en lo que en Argentina se llama "instituto de menores" (institutos correccionales) por su edad y tipo de delito (descendientes).

${ }^{31}$ Sanmartín, J. (editor), Violencia contra niños. Ariel, Barcelona, 1999, pp. 1-232. Triplett, R., R. Gainey; I. Sun. "Institutional strength, social control and neighborhood crime rates", en Theoretical Criminology, Londres, 7 (4), 2003, pp. 440-470.

${ }^{32}$ Kalinsky, B.; O. Cañete. Madres Frágiles. Un viaje al infanticidio. Biblos, Buenos Aires, 2010, pp. 1-141.

${ }^{33}$ O’Brien, op. cit. 
Se genera, junto a otras características, un estilo de vida que tiene como elementos relevantes al retraimiento, baja autoestima, depresión, relaciones deficitarias con los pares, con la familia y en la vida cotidiana en general.

Una de las mujeres entrevistadas había vivido en el campo, en una vivienda muy precaria al fondo de un lago, en una zona inbóspita y muy nevadora. Su concubino hacía algunas tareas de campo durante el día y ella atendía al bijo que había tenido de una unión anterior. Cuando llegaba su marido, en un invierno particularmente frío, dejaba a su bijo que "jugara" a la intemperie, con algunas mantas y después lo hacía dormir también afuera porque el marido quería "bacer cosas de la pareja". Finalmente fue denunciada por alguno de sus vecinos que pasaba cada tanto. El niño, entonces de tres años, perdió las dos piernas a la altura de las rodillas. Fue dado en adopción y ahora puede desempeñarse bien con las respectivas prótesis, con los cuidados que le otorgaron el hospital regional, luego el provincial y finalmente en uno de los hospitales de niños de la Ciudad Autónoma de Buenos Aires. El hombre no fue acusado porque se hizo un juicio abreviado donde ella asumió toda la responsabilidad. Más adelante, nos dijo que su madre, o sea la abuela del niño, le había aconsejado esta vía de solución porque para una mujer eran más importantes los hombres que los niños.

Los "presos condicionales" pueden no abandonar fácilmente los patrones carcelarios una vez que están en libertad (creencias, manierismos, actitudes y hábitos del lenguaje $)^{34}$. Cuanto más adaptados a la vida carcelaria es más difícil el retorno a la vida libre (institucionalización) ${ }^{35}$.

\section{CÁrcel vs. Libertad condicional}

La cárcel es un ámbito del todo inadecuado para preparar a las personas para la vida en libertad y lejos de las actuaciones delictivas; es una experiencia empobrecedora y debilitante ${ }^{36}$. El paso por esta institución mina la memoria sobre las reglas sociales y los recursos (memoria de la estructura social) y la vida cotidiana. La rapidez y complejidad de los cambios de la sociedad moderna impone impedimentos y barreras para la vuelta a la comunidad. La cárcel, como un mundo de incomunicación y ausentismo psicológico, crea hábitos de pensamiento y acción que son disfuncionales afuera ${ }^{37}$.

34 Añez Castillo; Han Chen; Morales; Nilson; Párraga Meléndez; Rodríguez 2008, Lea; García, op. cit., Maruna; Immarigeon, op. cit., Núñez, op. cit.

35 Stern, V. Creando criminales. Las cárceles y las personas en una sociedad de mercado. Ad-Hoc, Buenos Aires, 2010, pp. 1-246.

${ }^{36}$ Craig, H. "The Psychological Impact of Incarceration. Implications for postprision adjustment", en Travis, J. and M. Waul Prisoners once removed. The impact of incarceration and re-entry on children, families, and communities. The Urban Institute Press, Washington, 2003, pp. 33-66. Liebling y Maruna op. cit., Marchetti op. cit.

${ }^{37}$ Hoschtetler; DeLisi op. cit., Liebling y Maruna op. cit. 
Las cárceles pueden actuar como factor criminógeno tanto en sus aspectos primarios sobre los presos como secundarios sobre la vida de las personas allegadas ${ }^{38,}, 39$.

Es punitiva y agrega un plus de sufrimiento a lo que debería ser estrictamente el cumplimiento de una condena de privación de la libertad ambulatoria y no otra cosa. Peor aún, está siendo considerada como otra agencia del Estado que permite lidiar con los problemas de la pobreza y que de una forma u otra alivia los efectos que esta última genera $^{40}$.

Las personas recién salidas de la cárcel se consideran víctimas de un sistema inadecuado e injusto y por ende del papel de victimarios pasan al de víctimas (se puede ser ambas cosas a la vez), de modo que su familia y el conjunto social se vuelven hostiles si no se cumplen sus reclamos en forma inmediata y satisfactoria. La hostilidad es una variable que puede estar relacionada con la re-ofensa, ya que está alimentada por el encierro ${ }^{41}$.

Yo acá aprendí a no esperar nada de nadie. Ni de otros presos ni de los guardias. Acá tenés que arreglártela por la fuerza. Estar siempre despierto para que no te roben nada. Estar en guardia para que no te suspendan la visita. Hablar lo justo y con las palabras que se entiendan. Gritar para que te escuchen y callar para no meterte en problemas. Hay que aprender estas cosas. Si no lo hacés desde el primer día te convertís en un cachivache [algo desechable]. Todos te pegan, te usan, sos el punto de choque del pabellón. Ya ni siquiera me reconozco de cómo era antes. Bueno... no era ningún angelito. Era un tipo pesado. Ojo que nunca maté a nadie, pero al fin y al cabo tenía mi familia a la que daba de comer y los vestía con ropa de marca. A hora ya no me reconozco. Tuve mis salidas transitorias ${ }^{42}$ pero no pude aguantar a mi patrón. Me mandaba todo el día y eso me irritaba, me ponía furioso, tenía ganas de matarlo. Sentía deseos de volver acá. Salía volando para acá cuando de verdad creí que lo iba a matar. Aunque es más de lo mismo, o peor. Ni siquiera me llaman por mi nombre y yo a todos tengo que llamarlos "Señor". Pero me acostumbré. Paso el tiempo. Y de verdad ya ni cuento el tiempo para mi libertad condicional. No sé si quiero que llegue ese momento. Por abora, no tengo ningún deseo. Tengo la idea que, después de tanto tiempo, yo soy de acá. Afuera ya no tengo nada.

(Parte de una entrevista a G., 38 años, durante la ejecución de su pena privativa de la libertad de 15 años de cumplimiento efectivo, y a pocos meses de la posibilidad de obtener su libertad condicional. Marzo de 2011).

${ }^{38}$ Haney, op. cit.

${ }^{39}$ Carlen, P.; J. Tombs, op. cit.

${ }^{40}$ Carlen, P.; J. Tombs, op. cit., Irwin, J.; B. Owen, "Harm and the contemporary prison", en Liebling, A. y S. Maruna. The effects of Imprisonment. William Publishing, Nueva York, 2005, pp. 94-117.

Leal; García, op. cit., Liebling, A.; Sh. Maruna op. cit.

Travis; Waul, op. cit.

${ }^{41}$ Hoschtetler, A.; M. DeLisi, op. cit.

42 Período de beneficios previo a la libertad condicional donde se sale a trabajar y se vuelve a la cárcel sin vigilancia (Ley N $\mathrm{N}^{\mathrm{2}} 24660 / 95$ y sus modificatorias). 
El período de libertad condicional se ha definido como "caótico" ${ }^{43}$. La liberación es una situación que marca un corte radical con la racionalidad carcelaria y obliga al ahora expreso a reorganizarse sin tener medios para hacerlo. La rutina operacional de la cárcel y la nulidad de opciones deja profundas huellas desfavorables en la identidad individual y social de las personas. Deben acarrear el estigma de ser "expreso" que tiene fuertes connotaciones referidas a la "peligrosidad", consumo de drogas y alcohol, uso de armas, lo que genera un rechazo y alejamiento ya sea por temor a ser víctima o porque los hijos de los demás establezcan relaciones con los hijos de esta familia etiquetada como "criminal".

El haber estado en la cárcel desestabiliza todo intento de transformarse en una persona útil, productiva, que aporta recursos a su familia y que se empiece a respetar en la comunidad por el cumplimiento de estos valores. De ahí que la línea de continuidad entre cárcel y comunidad sea tan visible en estos casos y ambas se conviertan en un vehículo de mayor opresión, siendo que una refuerza a la otra ${ }^{44}$. La cárcel no ofrece espacios para la narrativización de lo ocurrido y para tomar una perspectiva diferente y responsable. No da lugar a la expresión de las emociones ni al sufrimiento, más bien al contrario. Y en el período de libertad condicional ya no tienen tiempo ni oportunidad.

Algunos autores sostienen que lo que sucede afuera de la cárcel en términos de vivienda, trabajo y relaciones sociales conduce, en realidad, a facilitar el quiebre de la ley mientras que los escasos o nulos programas carcelarios y postcarcelarios hacia la "rehabilitación" casi no tienen peso sobre las vidas individuales y familiares ${ }^{45}$.

De modo tal que la reducción de la reincidencia no puede ser una función primaria de la cárcel porque los requerimientos que ellas tienen son primordialmente las de mantener a la gente bajo custodia y vigilancia, además de alejadas del resto de la sociedad; siendo así, el eventual carácter terapéutico queda suspendido o anulado. No puede pretenderse que un tiempo de encierro pueda servir como propuesta inclusiva; la falta de capacitación y la recuperación de un sentido social aceptable tampoco puede adquirirse en la vida libre "a prueba".

Hay autores que sugieren que la carrera criminal y su eventual continuidad no son necesariamente elegidas sino que puede ser también el resultado del encarcelamiento y la vuelta a la cárcel que se predican de los problemas estructurales experimentados por los presos que son liberados ${ }^{46}$. A muchos expresos nunca se les presenta una oportunidad genuina para retornar a sus casas y empezar una nueva vida. Estas personas recaen en la reincidencia y algunas de ellas se vuelven institucionalizadas. De hecho, cuanto más

${ }^{43}$ Scott, G. op. cit.

${ }^{44}$ Marchetti, A-M. op. cit.

${ }^{45}$ Carlen; Tombs, op. cit., Piña Ysea, E. R.; L. Rivas. "Responsabilidad del Estado venezolano en proveer asistencia integral postpenitenciaria en la fase de ejecución penal”, en Capítulo Criminológico, Universidad de Zulia, Vol. $35 \mathrm{~N}^{\circ}$ 3, 2007, 409-432. Robinson, G. op. cit.

Scott, op. cit., Zhang, S.; R. Roberts; V. Callanan op. cit.

${ }^{46}$ Rose, D.; T. Clear, op. cit., Travis, J.; M. Waul op. cit., Travis; Waul, op. cit. 
altas en tiempo sean las condenas y mayores las medidas de seguridad, menores serán las oportunidades para un retorno exitoso a la vida en libertad.

Si bien el regreso ya se inicia en la cárcel, en general no se tiene claro que la mayoría de las condenas, tarde o temprano, se agotan y las personas retornan a la vida en libertad. Nadie ayuda para armar, durante la internación carcelaria, un plan realista para minimizar el riesgo de fracaso durante su retorno a la comunidad. El reingreso es un proceso que debe tener algún sentido para quien sale de la cárcel como para quienes lo reciben en el barrio o el vecindario ${ }^{47}$.

Las cárceles no pueden reducir la reincidencia; ni siquiera intentarlo.

\section{Reflexiones FinAles}

En este trabajo se ha tratado de sistematizar y actualizar los principales problemas sociales así como los vacíos de investigación de la vida postpenitenciaria, en la etapa de "libertad condicional” según la terminología usada en la República Argentina, mostrando una línea de continuidad entre la racionalidad carcelaria y la vida posterior en las comunidades donde los expresos intentarán reubicarse.

Por medio de la enumeración y actualización de diversas investigaciones de algunas de las principales cuestiones que se transforman en obstáculos para la reinstalación de los "detenidos condicionales" se ha pretendido ofrecer un estado de la cuestión lo más acabado y reciente posible.

Se ha querido mostrar un espacio - simbólico y material- común entre ambas situaciones debido a que, si bien se quiere creer que la cárcel promueve conductas y formas de ser que se consideran caminos a la "rehabilitación" (cumplir horarios, hacer a tiempo tareas específicas, mantenerse fuera de escenarios de violencia), es cierto, también, que las sentencias se agotan y las personas vuelven a las comunidades para seguir, en lo posible, con sus vidas; cargando estas maneras carcelarias que son del todo inútiles, y promotoras de conflictos, para la vida en la sociedad libre. No hay posibilidades que la cárcel actúe de otra forma que no sea la estrictamente punitiva.

Si bien la reincidencia o, en forma más general, la repetición del delito tiene múltiples causas, una de ellas puede ser justamente la estadía carcelaria.

Asimismo, podrán tomarse en cuenta otros factores, además de los enumerados por casi todos los autores que se dedican a investigar este tema y hallados por nosotros mismos, tales como vivienda y trabajo estable como queda dicho. Estos otros factores tienen que ver con necesidades relativas a una adquisición más amplia de los derechos ciudadanos y de su efectivo cumplimiento por parte del Estado. Abandonar el camino del delito y por ende la cárcel para desarrollar una vida en la legalidad, aun conservando, por inalterables, las huellas del delito y el encarcelamiento, no dependen solo de una conducta aceptable y que se espera socialmente; también tiene que ver con decisiones morales acerca de lo

\footnotetext{
47 Taxman; Young; Byrne, op. cit.
} 
que está bien y lo que está mal, que pueden tomarse solo cuando hay un horizonte de perspectivas asentidas con otros ciudadanos y un sentido compartido de lo que en un momento y lugar geopolíticos determinados se considere como "bien común".

Aun en una situación de franco pesimismo respecto de la posibilidad de desetiquetamiento y reconciliación con la víctima o sus familiares y la comunidad, de penas alternativas, de descriminalización de las comunidades de pertenencia, de un mejoramiento de las instituciones carcelarias, que no sea sinónimo de reafirmar la permanencia del sistema carcelario, y del escaso o nulo interés de las políticas públicas postpenitenciarias, estas reflexiones parecen importantes para dar una mayor visibilidad y consideración públicas a la etapa de la libertad condicional.

\section{BIBLIOGRAFÍA}

AÑez Castillo, M. A., Han Chen, P., Morales Manssur, J. et al., "Asistencia laboral penitenciaria y postpenitenciaria: una propuesta a la reintegración social del recluso", en Capítulo Criminológico, Universidad de Zulia, Vol. 36 No 4, 2008, pp. 51-88.

Birbeck, CH., "El desempeño penal bajo el destacamento de trabajo en la región andina de Venezuela (1999-2002)", en Capítulo Criminológico. Universidad de Zulia, Vol. 31 No 4 , 2003, pp. 33-74, 2003.

Carlen, P., Tombs, J., "Reconfigurations of penalty. The ongoing case of the women's imprisonment and reintegration industries”, en Theoretical Criminology, Londres, Vol. 10 (3), 2006, pp. 337-360.

Carlton, B., Segrave, M., "Women’s survival post-imprisonment: Connecting imprisonment with pains past and present", en Punishment and Society, Londres, 13 (5), 2011, pp. 551-570.

Clear, T., Rose, D. J. Ryder, "Incarceration and the Community: The Problem of Removing and Returning Offenders, en Crime E Delinquency, Londres, Vol. 47, No 3, 2001, pp. 335-351.

Colmenarez, J. “Actitud familiar ante la llegada del liberado al hogar (Estudio de casos)”, en Capítulo Criminológico, Universidad de Zulia, Vol. 33, No 1, 2005, pp. 79-113.

Comfort, M. "Papa's house. The prison as domestic and social satellite”, en Ethnography 3 (4), Londres, 2002, pp. 467-499.

Craig, H. "The Psychological Impact of Incarceration. Implications for postprision adjustment", en Travis, J. and M. Waul, Prisoners once removed. The impact of incarceration and re-entry on children, families, and communities. The Urban Institute Press, Washington, 2003, pp. 33-66.

Hammett, Th., Roberts, Ch., Kennedy, S., "Health-Related Issues in Prisoner Reentry", en Crime E Delinquency, Londres, Vol. 47 No 3, 2001, pp. 390-409.

Haney, C., "The contextual revolution in psychology and the question of prison effects", en Liebling, A. y Sh. Maruna. The effects of Imprisonment. William Publishing, Nueva York, 2005, pp. 66-93.

Hasley, M., "Negotiation conditional release. Juvenile narratives of repeat incarceration", en Punishment E Society, Londres, Vol. 8 (2), 2006, pp. 147-181.

Hipp, J., Jesse, J., Shah, R., Turner, S., "Parolee’s physical closeness to social services. A Study of California parolees", en Crime E Delinquency. Londres, Volume XX, Number X, 2008, pp. 1-29.

Hoschtetler, A., DeLisi, M., "Social Support and feelings of hostility among released inmates", en Crime E Delinquency, Londres, Vol. XX Number X, 2008, pp. 1-19. 
Irwin, J., Owen, B., "Harm and the contemporary prison”, en Liebling, A. y S. Maruna. The effects of Imprisonment. William Publishing, Nueva York, 2005, pp. 94-117.

Kalinsky, B., CAÑete, O., Madres Frágiles. Un viaje al infanticidio. Biblos, Buenos Aires, 2010, pp. 1-141.

Leal, L., García, A., "Condiciones objetivas y subjetivas del funcionamiento de la medida destacamento de trabajo desde la perspectiva de los destacamentarios”, en Capítulo Criminológico, Universidad de Zulia, Vol. $36 \mathrm{~N}^{\circ}$ 1, 2008, pp. 11-37.

Leverentz, A., "Neighbourhood context of attitudes toward crime and re-entry", en Punishment E Society. Londres, 13 (1), 2001, pp. 64-92.

Liebling, A., Maruna, SH., The effects of Imprisonment. William Publishing, Nueva York, 2005, 177-208.

Marchetti, A.-M., "Carceral impoverishment. Class inequality in the French penitentiary", en Ethnography 3 (4), Londres, 2002, pp. 416-434.

Maruna, Sh., Immarigeon, R. (edited by), After Crime and Punishment. Pathways to offender reintegration. William Publishing, Nueva York, 2004, pp. 1-320.

Maruna, SH., "Reentry as a rite of passage", en Punishment E Society, Londres, 13 (1), 2011, pp. 3-28.

Mills, A., Codd, H., "Prisoner's families and offender management: mobilizing social capital", en Probation Journal. The Journal of Community and Criminal Justice. Londres, Vol. 55 number 1, 2008, pp. 9-24.

NúÑEZ, G. M., "Las fórmulas alternativas de cumplimiento de pena en el sistema penitenciario venezolano", en Capítulo Criminológico., Universidad de Zulia, Vol. 33 No 1, 2005, 31-53.

O'Brien, P., Making it in the "Free World", Women in transition from prison. New York, State University of New York Press, Nueva York, 2001, pp. 2-201.

OpSAL, T., "Women disrupting a marginalized identity: subverting the parolee identity through narrative, en Journal of Contemporary Ethnography, Londres, 40 (2), 2001, 136-167.

Pertisilia, J., When Prisoners come home: Parole and Prisoner Re-entry. Oxford University Press, Oxford, 2003, pp. 1-278.

PIÑA Ysea, E. R., Rivas, L., "Responsabilidad del Estado venezolano en proveer asistencia integral postpenitenciaria en la fase de ejecución penal”, en Capítulo Criminológico, Universidad de Zulia, Vol. 35 N $^{\circ}$ 3, 2007 409-432.

Richie, B., "Challenges Incarcerated Women Face as They Return to Their Communities: Findings From Life History Interview", en Crime E Delinquency, Londres, Vol. $47 \mathrm{~N}^{\circ} 3$, 2001, pp. 368-389.

Robinson, G., "Late-modern rehabilitation. The evolution of a penal strategy", en Punishment E Society, Londres, Vol. 10 (4), 2, 2008, 429-445.

Rose, D., Clear, T., "Incarceration, Re-entry, and Social Capital. Social Networks in the Balance", en Travis, J. and M. Waul, Prisoners once removed. The impact of incarceration and re-entry on children, families, and communities. The Urban Institute Press, Washington, 2003, pp. 313-341.

Rossman, S., "Building Partnerships to strengthen offenders, families, and communities", en Travis, J. y M. Waul, Prisoners once removed. The impact of incarceration and re-entry on children, families, and communities. The Urban Institute, Washington, 2003, pp. 342-379.

SANMARTín, J. (editor), Violencia contra niños. Ariel, Barcelona, 1999, pp. 1-232.

Sсотт, G., "It's a sucker's outfit". How urban gangs enable and impede the reintegration of exconvicts, en Ethnography, Londres, Vol. 5 (1), 2004, pp. 107-140.

Smith, P., Schweitzer, M., "The Therapeutic Prison", en Journal of Contemporary Criminal Justice, Londres, Vol. $28 \mathrm{~N}^{\circ}$ 1, 2012, pp. 7-22. 
Stern, V., Creando criminales. Las cárceles y las personas en una sociedad de mercado. Ad-Hoc, Buenos Aires, 2010, pp. 1-246.

TAXman, F., Young, D., Byrne, J., "With eyes wide open: formalizing community and social control intervention in offender reintegration programmes”, en Maruna, Sh., R. Immarigeon, (edited by), After Crime and Punishment. Patbways to offender reintegration. William Publishing, Nueva York, 2004, pp. 233-260.

Travis, J., Waul, M., Prisoners once removed. The impact of incarceration and re-entry on children, families, and communities. The Urban Institute Press, Washington, 2003, pp. 157-188.

Triplett, R., GAiney, R., Sun, I., "Institutional strength, social control and neighborhood crime rates”, en Theoretical Criminology, Londres, 7 (4), 2003, pp. 440-470.

Trulson, Ch., Delisi, M., Caudill, J., Belshaw, S., Marquart, J., "Delinquent Careers Behind Bars”, en Criminal Justice Review, Londres, 35 (2), 2010, pp. 200-219.

Vigne, N., Naser, R., Brooks, L., Castro, J., "Examining the Effect of Incarceration and In-Prison Family contact on Prisoner's Family relationships", en Journal of Contemporary Criminal Justice, Londres, Vol. 21 N 4, 2005, pp. 314-335.

Zhang, S., Roberts, R., Callanan, V., "Preventing Parolees from returning to prison through Community-Based Reintegration”, en Crime E Delinquency, Vol. 52, N 4, 2006, pp. 551-571. 